\section{Pamela Silver}

A continual commitment to exploring new scientific territory has led Pamela Silver on an oscillating path from physics and engineering to molecular biology and now to the development of engineering principles in the creation of cellular metrics.

When a young Pamela Silver received a slide rule as a prize for winning a mathematics competition, it is unlikely that she envisioned the integral role that measuring and counting in cellular systems would play in her later career. Yet now as one of the founding members of the Department of Systems Biology at Harvard Medical School, she and her co-workers are pioneering efforts to get cells to tell us how they are taking stock of their status and surroundings. Indeed, by combining her expertise in topics such as nuclear transport and genome organization with her enthusiasm for investigating the behavior of biological systems on a per-cell basis, she is observing and manipulating the quiet machinery that keeps cells running.

Silver is no stranger to tackling new projects and concepts. She grew up in the burgeoning Silicon Valley, exposed to the most exciting mathematics and engineering advances of the day. After training first as a physicist and then as a chemist in her undergraduate curricula, she moved on to molecular biology in graduate school. In recalling these transitions, she notes, "I've never been a fan of defining strict disciplines. I remember when I was an assistant professor, people would always ask what department I was in, and I found that very frustrating." During her time as a 'biologist', Silver made significant strides in understanding nuclear transport (among other topics), first identifying that this transport is an active process and since investigating the various players in and details of this phenomenon. More recently, she has returned to engineering concepts within the scope of biological systems, with computer scientists, physicists and biologists working together in her lab to approach problems in systems and synthetic biology.

In describing these young fields, Silver notes that she and the other members of the department, as well as the extended group of faculty associated with the Systems Biology graduate program, are not concerned with defining the scope of the fields as a whole. Rather, as director of this new $\mathrm{PhD}$ program, she anticipated that by "having the focus be on students and young faculty, they would be the ones to define the new discipline." As a result, the department's approach to developing the fields from an organizational standpoint has been to encourage communication between previously established disciplines that have, as she says, "different traditions, different habits, and different course requirements," using programs like a summer 'boot camp' to help incoming students and faculty tackle unfamiliar concepts and a weekly 'Theory Lunch' that serves up an intellectual smorgasbord of topics.

Even without a strict definition of the emerging disciplines, the goal of Silver's research is clear. She uses the framework of systems biology, or the explanation of higher-level properties of biological systems by considering the smaller parts of the system, to approach broad topics such as how cells respond to drugs and small molecules. She points out, "You may think you know how that happens, but if you drill down into that problem from a mathematical and an engineering point of view, you might find that in a population, not all the cells are behaving the same. So what does that mean?" This desire to find out what cells are doing on a larger scale is complemented by synthetic biology, which Silver describes as, in part, an engineering approach. In this way of thinking, individual biological functions are encapsulated as 'parts' that perform a specific function. The parts are designed to be as rigorous and as independent as electronic circuitry, with the aim that they can be plugged into a specific cell to perform a certain function.

Putting these biological circuits into action takes both innovation and an environment in which people can feel comfortable trying new things. In talking through a variety of initial ideas, Silver and her co-workers asked, "Could we count something in the cell? Could you count the number of mitochondria?" This question, however, overlooked the fact that "cells already count. They cycle, they have circadian rhythms, they mediate metabolites, they die at a certain age. They're just not always telling us what they're counting." With this insight, Silver focused instead on trying to induce cells to report on what they are already counting. As she points out, "Counting requires an input and an incremental output in response to what is being measured." To test this idea, Silver and her co-workers introduced parts that were activated at specific times in the cell cycle to generate or degrade fluorescent proteins; by monitoring fluorescence,

\section{"Cells already count. They're just not always telling us what they're counting."}

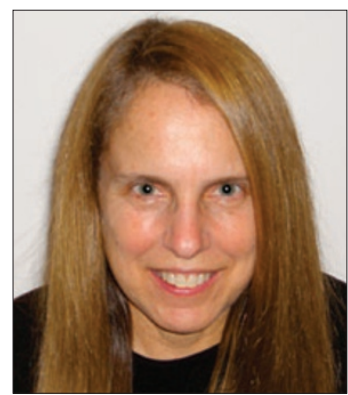

then, they were able to distinguish between mother (generation 1) and daughter (generation 2) cells, and they are currently working to expand the number of generations that can be counted.

Taking a slightly different approach, another project in the lab harnesses Silver's expertise in nuclear transport by focusing on trafficking between the nucleus and the cytoplasm; in this scenario, the counting occurs not because of the presence or absence of a particular molecule, but by the oscillations of that molecule between different cellular locations. Silver notes that these are only two ways that biological systems could count; indeed, in addition to incrementing numerical values, cells also measure their environment. Silver has expanded this function to artificially monitor exposure to exogenous compounds. She explains, "What we've been able to do is make cells that, when you expose them to a small molecule, they initiate an artificial positive feedback loop. As a result, they will turn on a signal in response to the small molecule, and when you remove the stimulus, the signal remains. That's the steady state version of memory."

Although Silver has been successful in oscillating between fields, her convictions on the value of this capability do face some opposition; as she points out, "The current structure of science in the United States really discourages switching fields. It doesn't allow people to be bold, and move around. If you have a new idea, what do you do? Instead, we need to have a system that rewards risk taking, and we have to be more tolerant of failure." She laments that this lack of risk taking carries over into a lack of innovation and even a lack of enthusiasm for science. Silver cautions, "Presumably people went into science because there was something that made them curious. We shouldn't forget about the pure mystery of science at all levels." Indeed, whether it be observing population behavior or developing new cellular measures, it seems that Silver still has many mysteries to explore.

Catherine Goodman, Boston, Massachusetts 